\title{
Needs of ergonomic design at control units in production industries
}

\author{
Levchuk $\mathrm{I}^{1}$, Schäfer A, Lang K-H, Gebhardt Hj and Klussmann A \\ Institute of Occupational Health, Safety and Ergonomics (ASER), Corneliusstrasse 31, D-42329 Wuppertal, \\ Germany
}

\begin{abstract}
During the last decades, an increasing use of innovative technologies in manufacturing areas was monitored. A huge amount of physical workload was replaced by the change from conventional machine tools to computer-controlled units. CNC systems spread in current production processes. Because of this, machine operators today mostly have an observational function. This caused increasing of static work (e.g., standing, sitting) and cognitive demands (e.g., process observation). Machine operators have a high responsibility, because mistakes may lead to human injuries as well as to product losses - and in consequence may lead to high monetary losses (for the company) as well. Being usable often means for a CNC machine being efficient. An intuitive usability and an ergonomic organization of $\mathrm{CNC}$ workplaces can be an essential basis to reduce the risk of failures in operation as well as physical complaints (e.g. pain or diseases because of bad body posture during work). In contrast to conventional machines, $\mathrm{CNC}$ machines are equipped both with hardware and software. An intuitive and clear-sighted operating of $\mathrm{CNC}$ systems is a requirement for quick learning of new systems. Within this study, a survey was carried out among trainees learning the operation of $\mathrm{CNC}$ machines.
\end{abstract}

Keywords: CNC-machine, human-machine-system, control panel, usability

\section{Introduction}

In the last decades, an increasing use of computer technology has led to a change in the production industry. The rapid development of microelectronic technology in 1970's opened new opportunities for man-machine-interaction.

Working with technical equipment and machines once was characterized by manual work and a lot of time was spend by tool setting, tool changing etc. [1]. Since then, manual work in the production was replaced by computer-controlled machines (figure 1).

Today, modern machines are equipped with complex computer controlled units, which make quick, highly complex and precise production processes possible. Manual work decreases while static work (e.g. long standing) and cognitive demands (e.g. observation of a production process) increase.

Machine operators have a high responsibility, because operating errors can lead to machine and/or product damage as well as to human injuries. High economic and/or human losses could result in consequence.

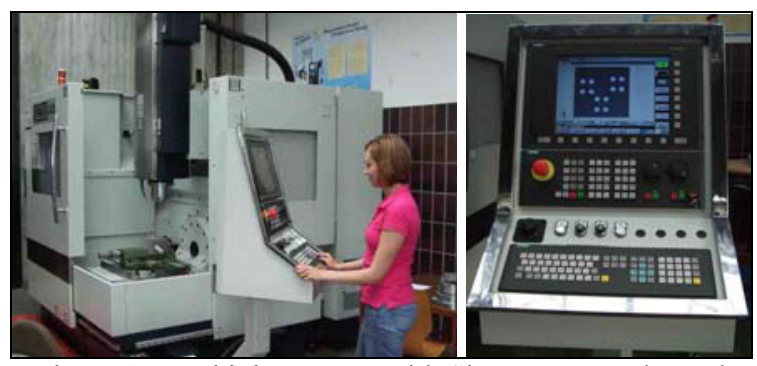

Figure 1. Machining center with Siemens control panel.

The current developments in the industrial production area go away from homogeneous mass production to a product usage production. This "lean production philosophy" leads to the fact that machines must be reequipped more frequently and quickly.

\footnotetext{
${ }^{1}$ Corresponding author: i.levchuk@institut-aser.de
} 
From the economic point of view, it is important that already the first work piece fits. This demand may increase the psychosocial stress to the employees working at the machines to avoid errors.

The widely discussed demographic change in Europe and particularly in Germany could be monitored in manufacturing areas, too. Over the next 20 to 30 years, the number of new trainees will decrease significantly [2]. Older employees will stay longer in their jobs than before and have to learn new technologies (lifelong learning).

An intuitive operability and clear-sighted organization of control panel can help to reduce the risk of operating errors and increase the learnability of operating $\mathrm{CNC}$ machines for trainees all ages. An ergonomic organization of $\mathrm{CNC}$ work places may decrease physical complaints, too.

The research questions in this study are:

- How is the usability of CNC units?

- Which incorrect operations arise and which damage occurs with it?

- Which ergonomic optimizations are needed?

\section{Method}

A standardized questionnaire was developed in cooperation with producers and operators of $\mathrm{CNC}$ machines. A survey was carried out in four training centres learning the operation of $\mathrm{CNC}$ machines. The content of the questionnaire were sociodemographic data, questions about leisure time activities (e.g. sports) and troubles during operating the $\mathrm{CNC}$ machines as well as questions about the most occurring errors and related consequences. Besides, the organisation of the workplaces and the control panels were documented.

\section{Results}

112 male trainees (age 17 to 56 years) from four training centers were included in the first evaluation (because of uneven gender distribution, female trainees were excluded from the analysis). For the analysis, the data from the survey were differentiated by age and/or body size groups. Body size groups were separated according to current measurements in Germany ([3], [4]).

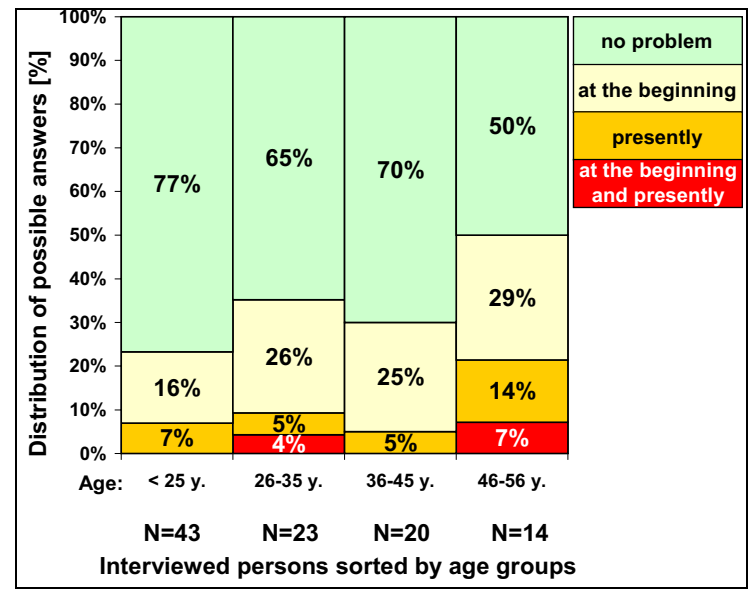

Figure 2. Bad readability of symbols and characters on the screen. Results are sorted according to age group.

\subsection{Design of information on display device}

The analysis showed correlations between readability of symbols on display and their size and type. This may mean that bad readability may be caused by size and type of symbols. $21 \%$ of the elderly trainees (46-56 y.) in comparison with young trainees $(<25$ y.) still have problems with readability of symbols and characters on the display (figure 2).

$50 \%$ of the elderly trainees (46-56 y.) agreed that characters because of their size and type are hard to recognize (figure 3). As result, rather elderly trainees required better readability by using larger displays.

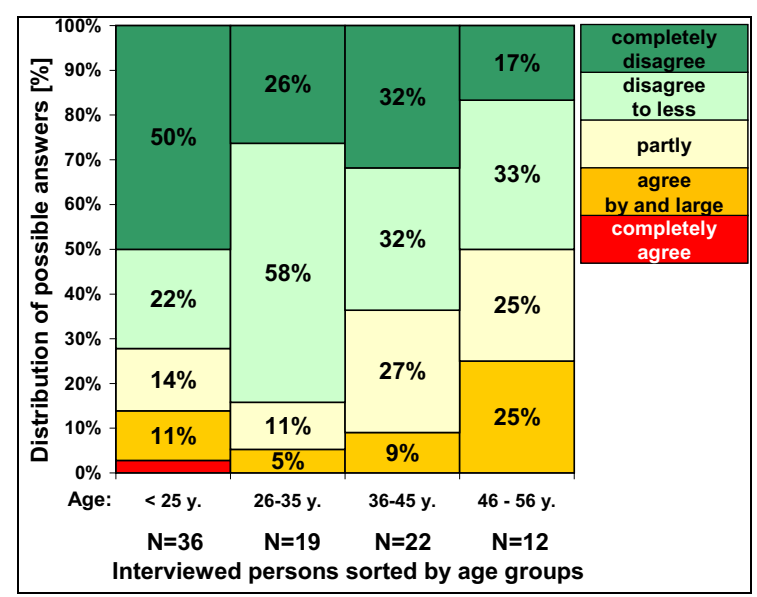

Figure 3. Symbols on the operating panel are hard to recognize because of the size and type. Results are sorted according to age group. 


\subsection{Design of control panel}

Most common control elements of the CNC machines considered were touch screens, alphanumeric keyboards (ANT), and software and function keys (S- \& F-keys).

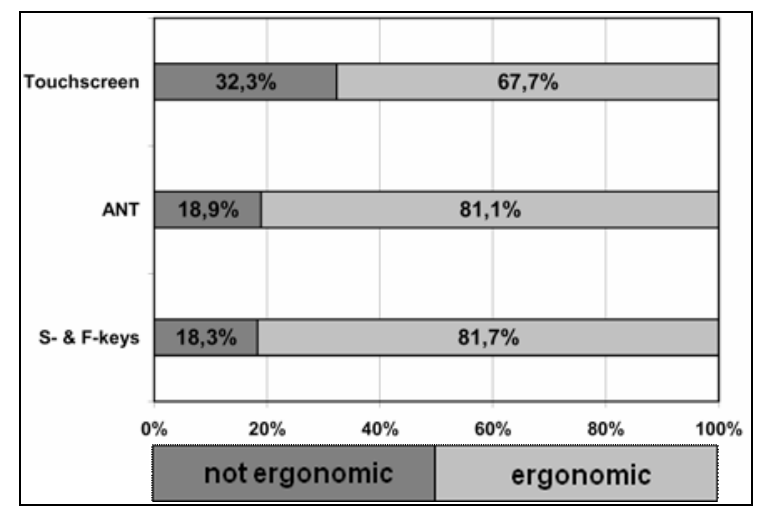

Figure 4. Usability of operating elements.

Alphanumeric keyboards (18,9\%) and S- \& Fkeys $(18,3 \%)$ were rated as not ergonomic because of their arrangement and/or their high appearance. Control elements, related to their width, length or diameter, were characterized as not ergonomic $(12 \%)$. If a touch screen was available, it was described as rather ergonomic, but the unintentional activating of neighboring keys/functions was criticized (figure 4).

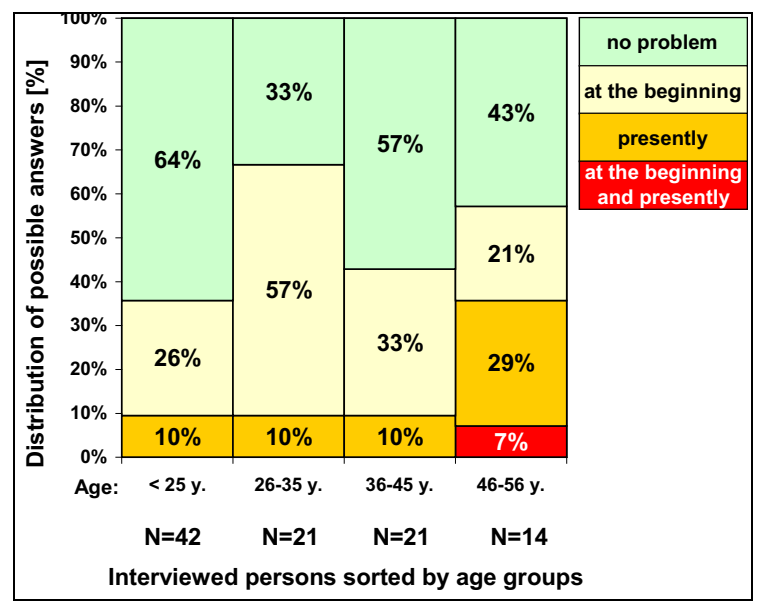

Figure 5. Confused arrangement of control elements on the control panel. Results are sorted according to age group.
About $35 \%$ of elderly trainees criticized the control elements on the control panel because of their confusing arrangement (figure 5).

As a result, rather elderly trainees require a better design with larger keys and a better arrangement of the keys.

\subsection{Design of work place}

Most of the considered CNC machines had nonheight-adjustable control panels. This could be the reason for the fact that only $52 \%$ of the interviewees were satisfied with the height of the control panel during their work. Furthermore, $74 \%$ of the trainees, who described the height of the control panel as not appropriate, rated their body posture as (rather) strained.

The trainees were also asked about the organization of the workplace and operating surface of the CNC units. $33 \%$ of the interviewees rated the "space within reach" as "rather bad" or "very bad". $65 \%$ of all trainees felt, that their body posture during the operation of the machine is (rather) strained.

In the questionnaire, the trainees could choose and indicate one of three different types of appearance of the control panel (figure 6). Regarding the first type, almost all disorders in the lower back region were reported rather by trainees with high body size (over $181 \mathrm{~cm})$. At the second type on figure 6, approximately $50 \%$ of the trainees with a body size smaller than $176 \mathrm{~cm}$ reported almost all disorders. Nearly all trainees with high body size (over $181 \mathrm{~cm}$ ) reported disorders in the neck at working with the third type of appearance of control panel (figure 6).

Accordantly, most disorders in all requested body regions (neck, shoulders, upper back, arms, hands, lower back, legs, feet) were reported rather by young trainees (under $25 \mathrm{y}$.).

Programming errors, wrong entry of dimension data of tool and work pieces, operating errors as well as a mix-up of the axles were the most occurring errors, which usually led to tool, work piece and/or device damage, failures or even hang up (table 1). 


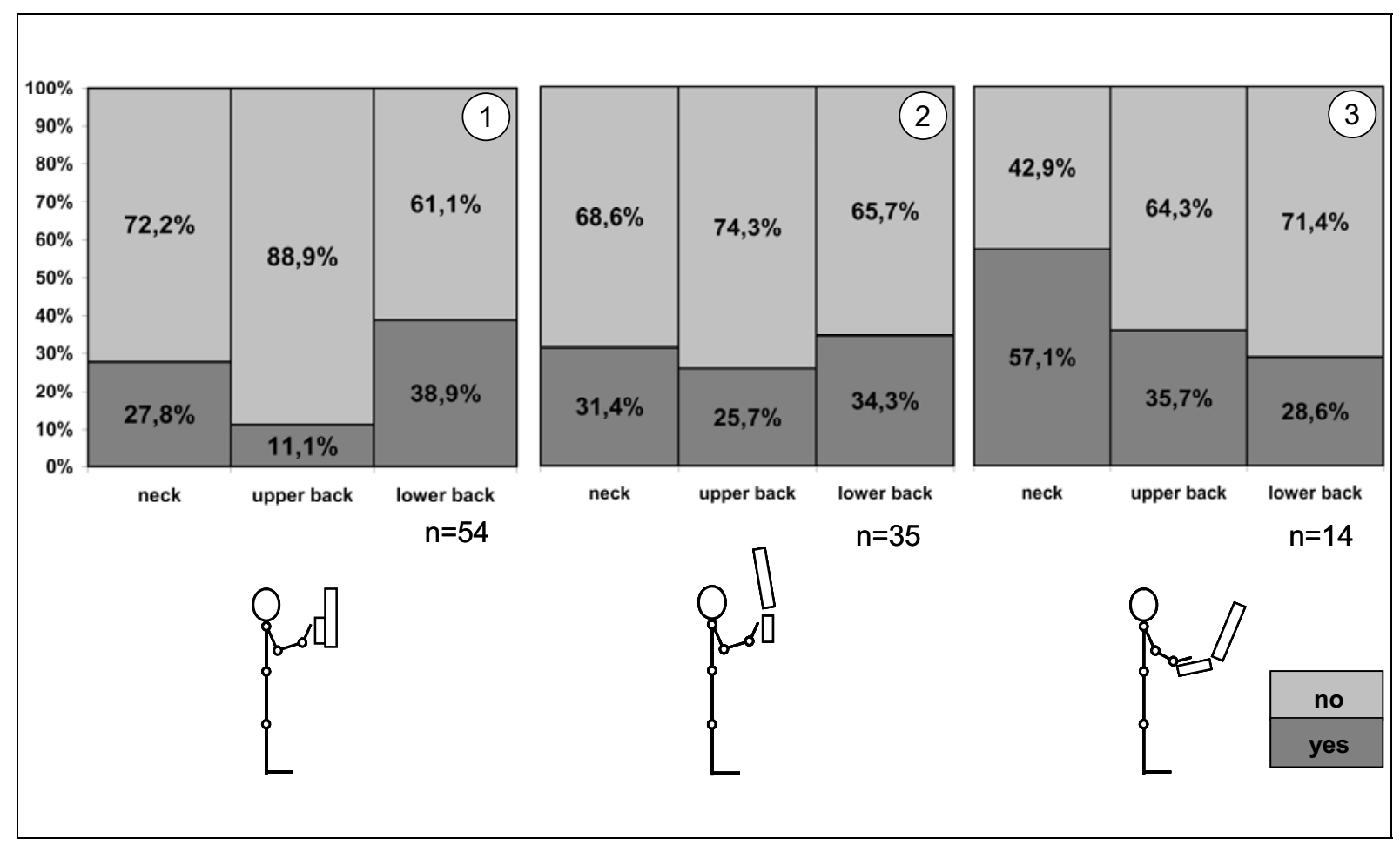

Figure 6

Musculoskeletal disorders in regard to arrangement of the work place.

Table 1

Operating errors arose and damages occurred with it.

\begin{tabular}{|l|c|c|c|c|c|c|c|}
\hline Cause & $\begin{array}{c}\text { Work piece } \\
\text { damaged }\end{array}$ & $\begin{array}{c}\text { Work tool } \\
\text { damaged }\end{array}$ & $\begin{array}{c}\text { Device } \\
\text { damaged }\end{array}$ & Failure & Hang up & $\begin{array}{c}\text { Outcome } \\
\text { not specified }\end{array}$ & Total \\
\hline Wrong data of work tool & 3 & 3 & 3 & 2 & 1 & 3 & 15 \\
\hline Programming error & 2 & 3 & 1 & 3 & 1 & 5 & 15 \\
\hline Wrong locking pressure & 3 & 2 & 1 & 1 & - & 3 & 10 \\
\hline Wrong zero point & 3 & 2 & - & 2 & - & 3 & 10 \\
\hline Wrong direction (+/-) & 1 & 2 & - & 1 & 1 & - & 5 \\
\hline Wrong data measured & - & 1 & - & 4 & - & 2 & 7 \\
\hline Operating error & 1 & - & - & - & 1 & 6 & 8 \\
\hline Wrong work tool & 1 & 1 & 1 & 1 & - & - & 4 \\
\hline Time pressure & 1 & 1 & 1 & - & - & - & 3 \\
\hline Total & 15 & 15 & 7 & 14 & 4 & 22 & 5 \\
\hline
\end{tabular}




\section{Conclusions}

This survey discovered that there is a need of optimization of the ergonomic design of $\mathrm{CNC}$ machines and the $\mathrm{CNC}$ control panel in particular. This regards the arrangement and appearance of operating elements and the operation of touch screens. Besides, the general organization of the workplace (height-adjustability of $\mathrm{CNC}$ control panels, arrangement to the working process) should be on focus.

As the results showed, rather elderly trainees must deal with more difficulties than young people when using the $\mathrm{CNC}$ control panel. Due to the demographic changes in Europe and particularly in Germany, special attention should be paid to this fact and should be considered in ergonomic measures.

\section{Acknowledgements}

This study is part of the "Design4All" project, which started in spring 2009 and will run until spring
2012. The Ministry of Economic Affairs, Energy, Construction, Housing and Transport of the State of North Rhine-Westphalia in combination with the „NRW Ziel 2 Programm“ of the European Regional Development Fund (ERDF) fund this project.

\section{References}

[1] Zschoge, S. (1994): Möglichkeiten der Anwendung moderner Formen der Arbeitsorganisation bei der Arbeit mit CNCMaschinen und deren Auswirkungen auf Mensch und Technik. Dresden.

[2] Langhoff, Th. (2009): Den demographischen Wandel im Unternehmen erfolgreich gestalten. Eine Zwischenbilanz aus arbeitswissenschaftlicher Sicht. Berlin, Heidelberg: Springer.

[3] DIN 33402-2:2005, Ergonomie. Körpermaße des Menschen Teil 2: Werte.

[4] Greil, H.; Voigt, A.; Scheffler, Ch. (2008): Optimierung der ergonomischen Eigenschaften von Produkten für ältere $\mathrm{Ar}$ beitnehmerinnen und Arbeitnehmer - Anthropometrie. Dortmund/Berlin/Dresden. 